\title{
Spatial and temporal analysis of Convolvulus arvensis L. populations over four growing seasons
}

\author{
M. Jurado-Expósito*, F. López-Granados, J.L. González-Andújar, L. García-Torres \\ Institute for Sustainable Agriculture, CSIC, Apdo. 4084, 14080 Córdoba, Spain
}

Received 25 February 2003; received in revised form 9 September 2003; accepted 2 October 2003

\begin{abstract}
Intensive field surveys of Convolvulus arvensis were conducted over the course of four growing seasons (1999-2002) in a 1.6 ha section of a field located in Andalusia, southern Spain, cropped with wheat in 1999 and 2001 and with sunflower in 2000 and 2002. In order to characterise the spatial and temporal variability of $C$. arvensis density, geostatistical techniques were used. Data from the study were used to design precise herbicide spraying. The density and spatial distribution of $C$. arvensis varied widely with years and crops. In general, weed density was higher in wheat years (30.41 and 53.72, in 1999 and 2001, respectively) than in sunflower ones (20.67 and 24.03, in 2000 and 2002, respectively). C. arvensis density data showed strong and moderate spatial dependence. The $C$. arvensis density maps achieved by kriging were used to estimate the percentage of surface susceptible to be treated with a site-specific herbicide treatment based on an estimated economic threshold (ET) for each year of study. The C. arvensis infested areas varied considerably between years and crops. About 33 and $64 \%$ of the total

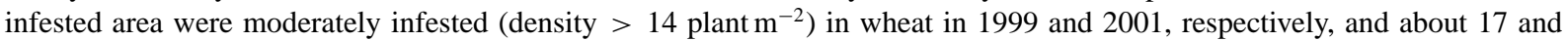
$19 \%$ in sunflower years (2000 and 2002, respectively). During the years cropped with sunflower the percentage of the total area infested with $C$. arvensis was reduced and therefore the area exceeding the economic threshold (AEET). So, if a given herbicide were applied just only to the areas exceeding the economic threshold, the average reduction in herbicide cost achieved in sunflower years could be around $81 \%$. These approaches demonstrated the importance of growing different crops in weed management outcome, and could be useful to farmers and researchers in formulating a multiple-season weed management plan, especially since $C$. arvensis has been shown to have relatively stable patches over time and crop rotations in no-tillage systems. (C) 2003 Elsevier B.V. All rights reserved.
\end{abstract}

Keywords: Convolvulus arvensis; Geostatistics; Kriging; Precision agriculture; Sunflower; Wheat

\section{Introduction}

Understanding the spatial and temporal dynamics of weed populations and the rate of their spread within fields is increasingly important as methods are being

\footnotetext{
* Corresponding author. Tel.: +34-957-499263; fax: +34-957-499252.

E-mail address: cs9disaj@uco.es (M. Jurado-Expósito).
}

developed for the site-specific management of weeds (Zhang and Wang, 2002). It is well known that weed populations have a patchy distribution (Mortensen et al., 1993, 1998; Cardina et al., 1995; Johnson et al., 1996; Jurado-Expósito et al., 2003) with aggregated weed patches of a varying size and density and areas with few or no weed seedlings. A weed patch is considered stable if is consistent with density and location over time (Rew and Cussans, 1995; Wyse, 1996; 
Gerhards et al., 1997). Stability is important from the perspective of patch management, so that a patch map from one year can be used to direct weed control in subsequent years (Lutman et al., 1998; Mortensen et al., 1998). This is especially true for perennial weeds in reduced tillage systems, where ploughing and cultivation are no longer management options and where farmers want to make informed decisions on the precise use of herbicides (Webster et al., 2000).

Most of the spatial variability studies about weed populations have provided very precise information for site-specific recommendations and they are referred to as density data (Heisel et al., 1996; Colbalch et al., 1999). However, they have been carried out in one crop without taking into account the crop rotations or evaluating the temporal variability over crop rotations.

Despite repeated disturbance weed patches generally persist. The relative importance of demographic processes that confer persistence will probably differ between weed species and will depend on the crop and weed management systems in which they occur. Recent studies have shown that more seedlings survive applications of pre- and post-emergence herbicides in high - rather than low-density populations (Dieleman et al., 1999) which may contribute to their persistence. Patchiness is also enhanced by the persistent seed or propagule banks. Annual variability in total seed production is expected to cause patches to expand in years of high populations and to contract in years of low production (Lutman et al., 1998). If weed patches are consistent with density and location over years, maps from one year or crop could be used to direct sampling plans and to regulate pre-emergence herbicide applications in subsequent years. Little data exist about the influence of crops on weed patches.

Spatial aggregation has been demonstrated for individual shoots in perennial weeds patches, such as Cirsium arvense L. (Donald, 1994), Apocynum cannabinum L. (Webster and Cardina, 1998; Dille et al., 2003) and Sorghum halepense (L.) Pers. (Horowitz, 1973). Shoots densities of perennial species tended to be high in the patch centre and decreased towards the edge (Donald, 1994).

Convolvulus arvensis L. is a very important perennial weed that infests wheat and sunflower in Spain (Jurado-Expósito et al., 2003; Hidalgo et al., 1990; Saavedra et al., 1989) and produces few viable seeds when growing in competition with agronomic crops and reproduces primarily vegetatively by underground rootstock. In addition, adventitious shoots arising from a network of rootstocks reduce crop yields and interfere with the harvest (Liebman et al., 2001). The development of the expert system SEMAGI (Castro-Tendero and García-Torres, 1995) permitted the prediction of the potential yield reduction from multi-species weed infestation (including $C$. arvensis) and the determination of the appropriate herbicide according to the different economic thresholds (ET) in sunflower and wheat under Andalusian conditions.

Reduced and no-tillage production has increased in Spain in the last 10 years and now accounts for 2 million of hectares of the annual crops (Anonymous, 1998). Wheat (Triticum aestivum L.) - sunflower (Helianthus annuus L.) is the main crop rotation in Andalusia (southern Spain). Many fields of wheat-sunflower rotations have been converted into no-tillage or reduced tillage, so perennial weeds like C. arvensis have become more troublesome since they cannot be reduced in abundance by repeated tillage or cultivation (Liebman et al., 2001).

The spatial distribution of weeds within cultivated sunflower has been characterised by Jurado-Expósito et al. (2003); however they did not deal with the spatial and temporal variability of weeds over time and crop, and this is needed to develop the basic information to support a site-specific management strategy in wheat and sunflower crops. Furthermore, there are no studies of $C$. arvensis patch spatial stability or temporal distribution in reduced tillage systems where this weed is most common.

The objectives of this study were to: (1) characterise the spatial and temporal variability of $C$. arvensis over four growing seasons in wheat and sunflower crops; (2) investigate the feasibility of developing accurate maps of C. arvensis; and (3) develop site-specific post-emergence herbicide application maps for areas that exceeded an economic threshold, over four growing seasons.

\section{Materials and methods}

\subsection{Study area and sampling scheme}

Intensive field surveys of $C$. arvensis plants were conducted during the course of four growing seasons 
(1999-2002) in a 1.6 ha section of a field located at Monclova (La Luisiana, Seville), within one of the most important and technologically advanced farming areas in Andalusia, southern Spain. According to the USDA soil series (1975) the soil was classified as Alfisol.

The field site was farmer-managed using no-tillage production methods. Wheat (Triticum aestivum L.) was sown in 1999 and 2001, and sunflower (Helianthus annuus L.) in 2000 and 2002. Conventional herbicides practices for weed control were used. Glyphosate was applied pre-emergence at $21 \mathrm{ha}^{-1}$ for the control of annual weed seedlings in wheat and sunflower. At those rates these herbicides had no significant activity on perennial shoots of $C$. arvensis.

Weed density was sampled in early May before crop harvesting. Wheat was in the last maduration process, sunflower was at 8-10 leaf stage and C. arvensis was $4-10 \mathrm{~cm}$ in height. An area measuring $65 \mathrm{~m}$ wide by $250 \mathrm{~m}$ long was selected for the intensive survey in 1999, and the same area was sampled again in 2000-2002, within a larger field (of around $40 \mathrm{ha}$ ), and its borders were at least $50 \mathrm{~m}$ from the main borders of the field. Rows were always oriented south-north across the study area during the course of the study.

C. arvensis density assessments were performed following a $7 \mathrm{~m} \times 7 \mathrm{~m}$ grid pattern, resulting in a total of 261 sampling units. The position of each grid point was georeferenced using a differential global positioning system (DGPS). At each node, the number of plants of $C$. arvensis were counted in a $2 \mathrm{~m} \times 2 \mathrm{~m}$.

The economic threshold, i.e. C. arvensis density causing a reduction in net wheat or sunflower yield amounting to the control treatment cost, was estimated at 14 plants $\mathrm{m}^{-2}$ (Castro-Tendero and García-Torres, 1995; Jurado-Expósito et al., 2003). So that, the $C$. arvensis density exceeded the ET required in weed control actions.

\subsection{Exploratory statistical analysis}

Weed density from each year was treated as a study case and was analysed statistically. Data distribution was described using classical descriptors (mean, maximum, minimum, standard deviation and skewness of data distribution). The descriptive statistics of weed density suggested that they were normally distributed (skewness between 1 and -2) and therefore no trans- formation was used for geostatistical analysis of $C$. arvensis density.

\subsection{Weed spatial and temporal distribution}

Spatial and temporal variability of $C$. arvensis density over the 4 years was described using the semivariogram. The semivariogram characterises the average degree of similarity between values $(C$. arvensis density) as a function of separation distance and direction. A semivariogram was calculated for each year of sampling as follows (Isaaks and Srivastava, 1989; Webster and Oliver, 2001):

$$
\gamma(h)=\frac{1}{2 N(h)} \sum_{i=1}^{N(h)}\left[z\left(x_{i}+h\right)-z\left(x_{i}\right)\right]^{2}
$$

where $\gamma(h)$ is the experimental semivariance value at distance interval $h ; N(h)$ the number of sample value pairs within the distance interval $h ; z\left(x_{i}\right), z\left(x_{i}+h\right)$ the sample values at two points separated by a distance interval $h$. All pairs of point separated by distance $h$ were used to calculate the experimental semivariogram. Several semivariogram functions were evaluated to choose the best fit with the data. One of the most important features of an empirical semivariogram is the pattern of anisotropy (directional influences) (Journel, 1986). Semivariograms were calculated both isotropically and anisotropically using VARIOWIN software (Software for Spatial Data Analysis in 2D, Spring Verlag, New York, USA). The anisotropic calculations were performed in four directions $\left(0,45,90\right.$ and $\left.135^{\circ}\right)$ with a tolerance of $22.5^{\circ}$ to determine whether the semivariogram functions depended on the sampling orientation and direction (i.e. they were anisotropic) or not (i.e. they were isotropic). The direction $0^{\circ}$ corresponds to $\mathrm{E}-\mathrm{W}$ and $90^{\circ}$ to the $\mathrm{N}-\mathrm{S}$ direction. A lag spacing of $5 \mathrm{~m}$ over a distance of $90 \mathrm{~m}$ produced the clearest semivariogram with a sufficient number of data points to be confident in the empirical semivariogram estimates. The experimental semivariograms were fitted by the least-squares procedure using VARIOWIN software.

In addition to providing information about the spatial aspects of a population, the empirical semivariograms were also used as a basis for fitting a semivariogram model necessary for kriging. Nested 
semivariogram structures were not used, as we were able to obtain adequate fits with a simple structure.

Spherical models were fitted to the experimental semivariograms for the 4 years of sampling of $C$. arvensis density. The parameters of the model: nugget semivariance, range and sill or total semivariance, which are needed to interpolate $C$. arvensis density counts in the kriging process, were calculated.

Semivariograms models were cross-validated comparing weed density values estimated from the semivariogram model to actual values. A trial-and-error procedure was used and the estimated parameters of the model were modified until adequate cross-validation statistics were obtained (Isaaks and Srivastava, 1989; Webster and Oliver, 2001), i.e. mean estimation error (MEE) not significantly different than zero; mean squared error (MSE) less than the variance of the sample values (Hevesi et al., 1992) and standardised mean squared error (SMSE) were within the interval $1 \pm 2 \sqrt{ } 2 / n$ ) (Isaaks and Srivastava, 1989; Hevesi et al., 1992).

Once cross-validated, model parameters were then used in kriging to provide estimates of $C$. arvensis density at an unsampled location. Ordinary point kriging was performed on a regular grid of $2.5 \mathrm{~m}$. Kriging was conducted using WINGSLIB (Geostatistical Software Library and User's Guide, Oxford University Press). Contour maps were generated using SURFER (Surface Mapping System, Golden Software Inc., 809 14th Street, Golden, CO 80401-1866, USA) contour mapping software based on WINGSLIB kriged value. Maps of kriged estimates provide a visual representation of the arrangement of the population and can be used to interpret trends in the semivariogram.

To define different classes of spatial dependence for $C$. arvensis the nugget variance was expressed as a percentage of the total semivariance. If the ratio was less than or equal to $25 \%, C$. arvensis density was considered as being strongly spatially dependent or strongly distributed in patches; if the ratio was between 25 and $75 \%$, the variable was considered to be moderately spatially dependent, and if the ratio was greater than $75 \%$, the variable was considered weakly spatially dependent (Cambardella et al., 1994; Cambardella and Karlen, 1999; González-Andújar et al., 2001; López-Granados et al., 2002; JuradoExpósito et al., 2003).

\subsection{Site-specific herbicide application}

The different $C$. arvensis density maps achieved by kriging were used to estimate the percentage of surface free of weeds and the percentage of surface susceptible to be treated with a site-specific herbicide treatment based on an estimated economic threshold for each year of rotation. Herbicide treatment was assumed to be needed for a $C$. arvensis density of 14 plants $\mathrm{m}^{-2}$, and the infested "area exceeding the economic threshold" (AEET) was determined.

\section{Results and discussion}

\subsection{Exploratory statistical analysis}

Density and spatial distribution of $C$. arvensis varied considerably with years. The mean $C$. arvensis density was $30.41,20.67,53.72$ and 24.03 plants $\mathrm{m}^{-2}$ in 1999, 2000, 2001 and 2002, respectively. Years and crops influenced the number of $C$. arvensis plants. In general, weed density was higher in wheat years (1999 and 2001) than in sunflower ones (2000 and 2002) (Table 1). The crop influenced the $C$. arvensis density.

\subsection{Weed spatial and temporal distribution}

Anisotropic semivariograms did not show any differences in spatial dependence with the directions, therefore isotropic semivariograms were chosen. The shape of the semivariogram was similar through the years and between crops (Fig. 1). However, the semivariance for each lag was much lower in 2000 and 2002 (sunflower crops) than in 1999 and 2001 (wheat crops) indicating that the difference between observations was greater in the wheat years of the study (1999 and 2001) than in sunflower years of the study (2000 and 2002). This is the result of a lower relative C. arvensis density and variance in sunflower years (2000 and 2002) compared to wheat years (Table 1).

C. arvensis density data displayed differences in spatial dependence as determined by semivariogram analyses (Table 1). Spherical isotropic models were defined for all the studies. Semivariogram parameters greatly varied among years and between crops (Table 1). For example, the sill parameters were higher 
Table 1

Statistical data of $C$. arvensis density (plants $\mathrm{m}^{-2}$ ), spatial distribution characteristics and cross-validation statistics

\begin{tabular}{|c|c|c|c|c|c|c|c|c|c|c|c|c|c|c|}
\hline \multirow[b]{2}{*}{ Year } & \multirow[b]{2}{*}{ Crop } & \multicolumn{4}{|c|}{ C. arvensis } & \multirow[b]{2}{*}{ Model } & \multicolumn{5}{|c|}{ Semivariogram parameters } & \multicolumn{3}{|c|}{ Cross-validation } \\
\hline & & Mean & Median & S.D. & Skew & & $\begin{array}{l}\text { Range } \\
(\mathrm{m})\end{array}$ & Nugget & Sill & $\begin{array}{l}\text { Nugget } \\
\text { ratio }^{\mathrm{a}}(\%)\end{array}$ & $\begin{array}{l}\text { Spatial } \\
\text { class }^{\text {b }}\end{array}$ & MEE & MSE & SMSE \\
\hline 1999 & Wheat & 30.41 & 29.00 & 37.41 & 0.81 & Spherical & 89.19 & 812.0 & 1581.1 & 51.35 & M & 0.022 & 1024.0 & 1.026 \\
\hline 2000 & Sunflower & 20.67 & 20.00 & 20.25 & 0.78 & Spherical & 158.70 & 134.7 & 538.2 & 25.02 & $\mathrm{~S}$ & 0.011 & 356.8 & 1.081 \\
\hline 2001 & Wheat & 53.72 & 42.00 & 54.81 & 0.53 & Spherical & 43.39 & 761.0 & 1176.0 & 64.70 & M & 0.098 & 1367.3 & 1.077 \\
\hline 2002 & Sunflower & 24.03 & 21.00 & 20.87 & 0.83 & Spherical & 37.79 & 158.4 & 394.8 & 40.12 & M & -0.121 & 267.3 & 1.033 \\
\hline
\end{tabular}

${ }^{\text {a }}$ Nugget ratio $=($ Nugget semivariance/total semivariance $) \times 100$.

b Spatial class: S, strong spatial dependence; M, moderate spatial dependence.

(1581 and 1176) in wheat (years 1999 and 2001) than in sunflower crop (years 2000 and 2002, 538 and 394 , respectively) this indicated that the population variance was higher in wheat than in sunflower. The nugget effect was greater than zero in all cases, mean-

\section{Wheat 1999}

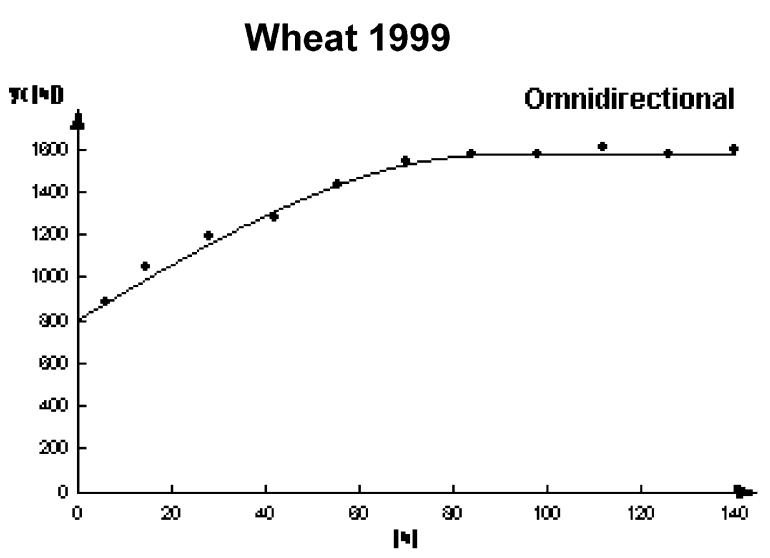

Wheat 2001

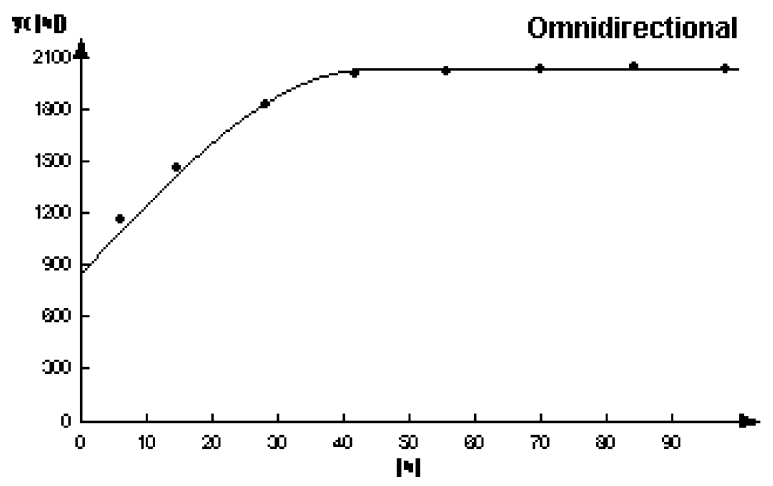

ing that observations separated by small distances were dissimilar (Isaaks and Srivastava, 1989). This variability might be due to differences in cropping or control actions among other processes influencing patchiness at scales smaller than $7 \mathrm{~m}$ or may simply

Sunflower 2000

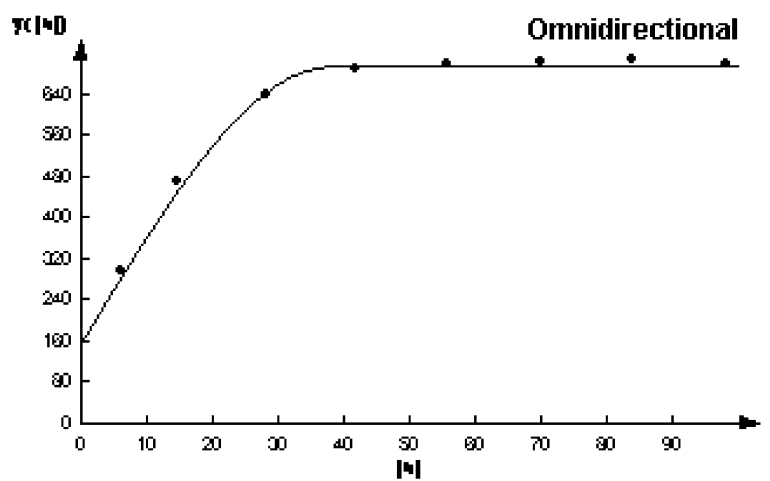

Sunflower 2002

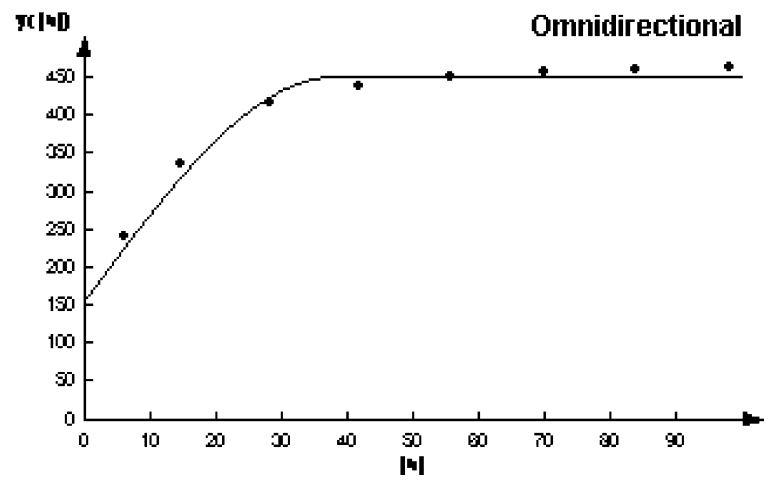

Fig. 1. Experimental (circles) and modeled semivariograms of C. arvensis density (plants $\mathrm{m}^{-2}$ ), corresponding to sampling from 1999 and 2001 in wheat, and 2000 and 2002 in sunflower. 
be the result of sampling error (Heisel et al., 1996; Cousens and Croft, 2000).

The nugget variance expressed as a percentage of the total semivariance was used to define distinct classes of spatial dependence for the $C$. arvensis density (Table 1). Medium nugget ratios (between 40 and $64 \%$ ) were found for wheat years of study (1999 and 2001) and for sunflower crop in 2002, which indicates a moderate spatial dependence and a high variability between sampling points. On the other hand, in the 2000 (sunflower crop) a nugget ratio of $25 \%$ was observed, indicating a strong spatial dependence of $C$. arvensis in that year.

The $C$. arvensis density maps for each year of study are shown in Fig. 2. A visual assessment reveals a distinct aggregation depending on years and crops. The C. arvensis populations were highly aggregated in sunflowers years (Fig. 2, 2000 and 2002). Although the range in density values was about the same in 2000 and 2002, the $C$. arvensis populations were more con- centrated (weed density per patch increased) in 2000 giving rise not only to a higher semivariance (differences between observations were greater) but also a steeper slope (greater degree of correlation between observations) in the semivariogram of 2000 compared to 2002 (Fig. 2). However, the $C$. arvensis populations in wheat years was not as concentrated and did not have these abrupt density changes (patch concentrations), but their changes were more gradual.

\subsection{Site-specific herbicide application}

The $C$. arvensis infested areas varied considerably between years and crops. About 63 and 52\% of the total area was free of $C$. arvensis in sunflower years (2000 and 2001), and about 37 and 18\% for wheat years (1999 and 2002) (Fig. 3).

About 33 and $64 \%$ of the total infested area were

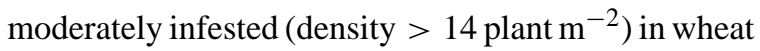
in 1999 and 2001, respectively, and about 17 and 19\%
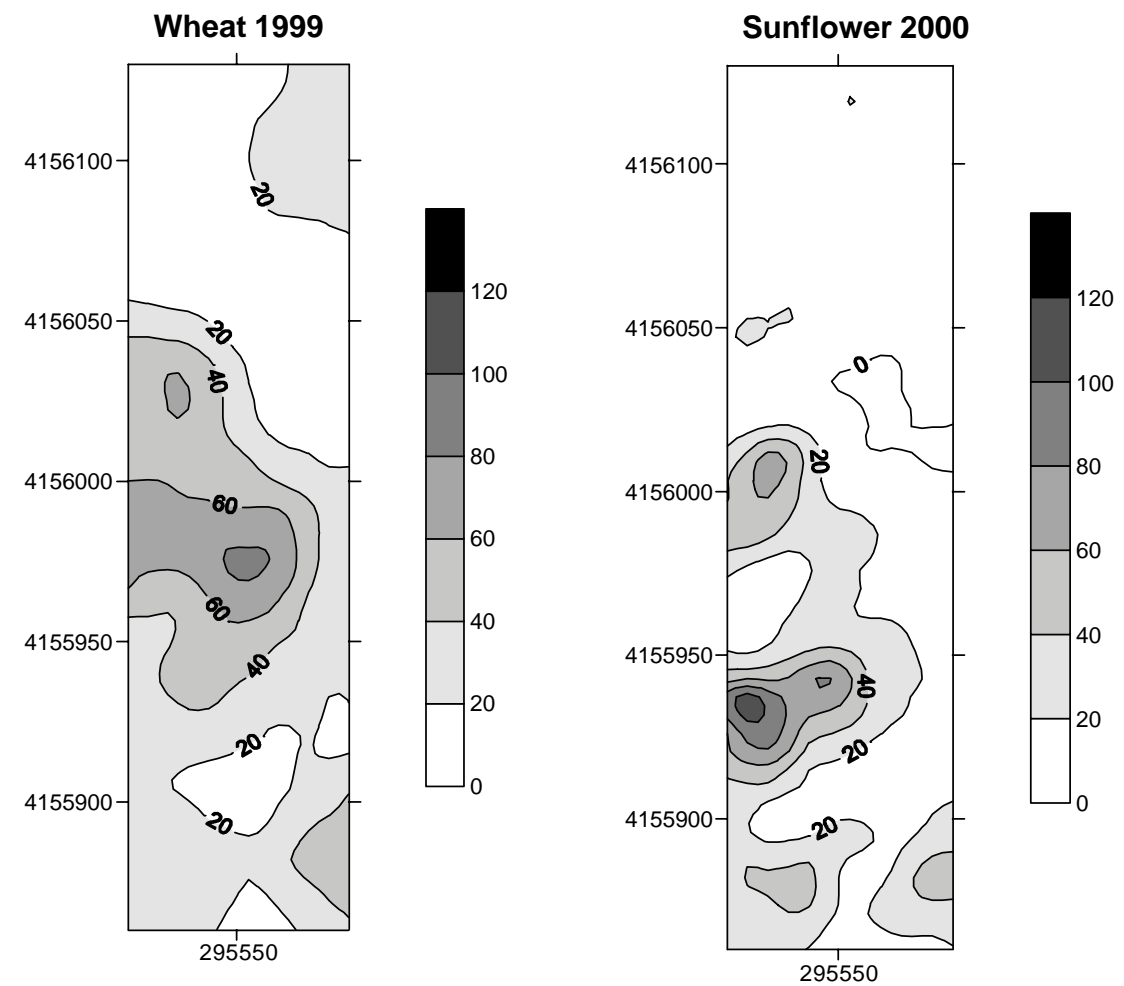

Fig. 2. Isoline maps of $C$. arvensis density (plants $\mathrm{m}^{-2}$ ), corresponding to sampling from 1999 and 2001 in wheat, and 2000 and 2002 in sunflower. Axis are in Universal Transverse Mercator units (m). Vertical axis, northings; horizontal axis, eastings. 

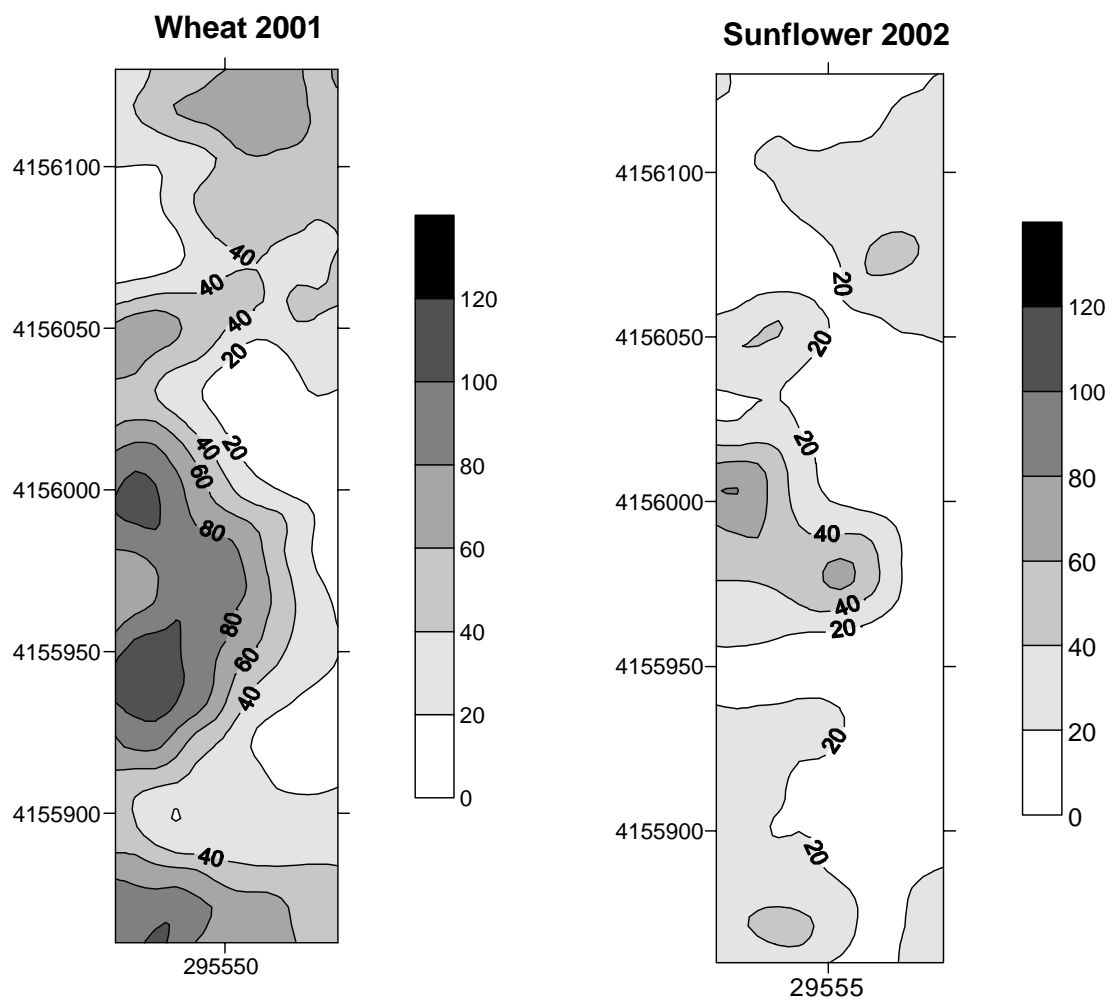

Fig. 2. (Continued).

in sunflower years (2000 and 2002, respectively). A C. arvensis density $>14$ plants $\mathrm{m}^{-2}$ justify a herbicide application (Fig. 3 and Table 2).

The rotation of wheat with sunflower crop reduced the percentage of total area infested with $C$. arvensis and therefore the area exceeding the economic threshold was lower. The crop rotation with sunflower was appropriate because it reduced the $C$. arvensis density. Therefore, if a given herbicide was applied just to the areas exceeding the economic threshold, the average reduction in herbicide cost achieved in sunflower years could have been around $81 \%$ (Table 2).

Weed patches are considerable stable if they are consistent with location and density over time (Wilson and Brain, 1991). It appeared that $C$. arvensis patches were stable with respect to their location. The main high-density focal points were easily relocated in the same crop, but some changes occurred in patch size, shape and location over the 4 years.
Spatial stability of the main high-density focal points was observed for each $C$. arvensis seedling patch map across the 4 years survey (Fig. 2). Single or multiple focal points of high-density were observed within the sampled area each year. Density decreased with distance from the focal point, gradually generat-

\section{Table 2}

Percentage of total area infested $(C$. arvensis density $\geq 1$ plants $\mathrm{m}^{-2}$ ) and percentage of area exceeding the economic threshold $\left(C\right.$. arvesis density $>14$ plants $\mathrm{m}^{-2}$ ) susceptible to be treated with herbicide

\begin{tabular}{llll}
\hline Year & Crop & $\begin{array}{l}\text { Total area } \\
\text { infested }(\%)\end{array}$ & $\begin{array}{l}\text { Area exceeding } \\
\text { the ET } \text { ET }^{\mathrm{a}}(\%)\end{array}$ \\
\hline 1999 & Wheat & 63.2 & 33.3 \\
2000 & Sunflower & 36.6 & 17.1 \\
2001 & Wheat & 82.1 & 64.3 \\
2002 & Sunflower & 47.5 & 19.4 \\
\hline
\end{tabular}

Total surveyed area was 1.60 ha.

a ET: economic threshold. 
Wheat 1999
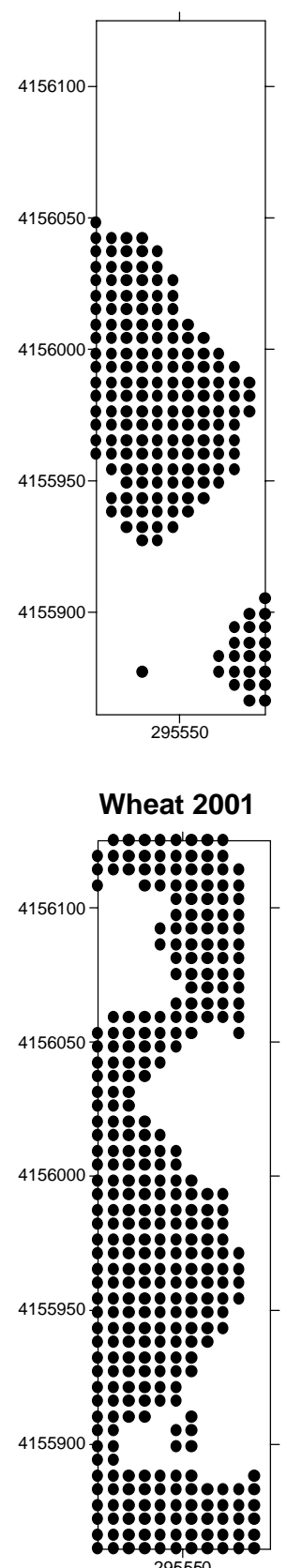

Sunflower 2000

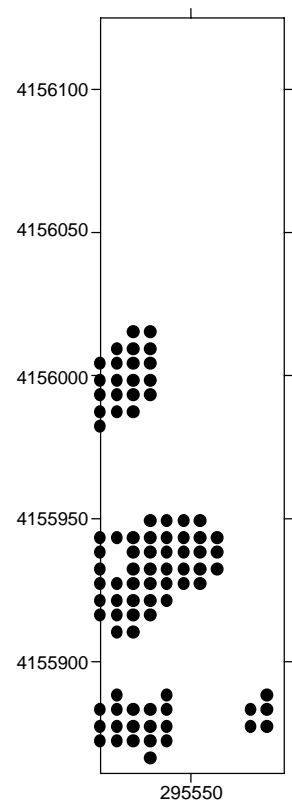

Sunflower 2002

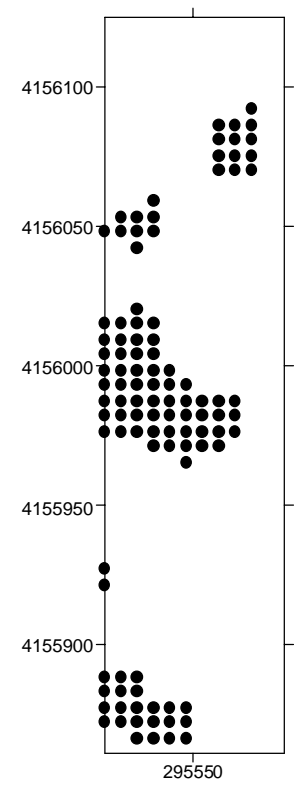

Fig. 3. Site-specific herbicide application maps obtained for $C$. arvensis density (threshold value $>14$ plants $\mathrm{m}^{-2}$, marked black), corresponding to sampling from 1999 and 2001 in wheat, and 2000 and 2002 in sunflower. Axis are in universal transverse mercator units (m). Vertical axis, northings; horizontal axis, eastings.

ing a fragmented edge of low densities and in some cases, reaching zero. These figures indicate that the shape of the main patches could be detected early in the field and that the patches shape remained relatively stable throughout the four growing seasons. When growing in competition with sunflower, $C$. arvensis patches were less and smaller (Fig. 3, sunflower 2000 and 2002) than in competition with wheat. A poor weed control, $C$. arvensis would have the potential to become an increasingly prevalent weed problem in wheat and sunflower crops in Spain under no-tillage systems.

\section{Conclusions}

Knowledge of predicted patch location at a given point during the growing seasons can be a guide weed scouting and weed management. This information could also be a component of a precision agriculture system by recommending the appropriate time (crop and rotation) for capturing remotely sensed images; these images could be useful in quantifying the percentage of a field that is infested with this weed as well as identifying areas within the fields with high numbers of $C$. arvensis patches. Although the identification of individual plants of $C$. arvensis in remotely sensed images would be difficult, it could permit the identification of $C$. arvensis patches.

Geostatistics is a powerful tool for studying the spatial and temporal variability of weed populations. Relationships between individual plants or groups of plants can be explored using variography methods and maps created by kriging procedures. In addition, the dynamics of these populations as a function of time or disturbance regimes can be evaluated. These geostatistical procedures revealed that patch edges varied considerably over 4-year of study.

Recognition of the importance of growing different crops in weed management outcome will assist researchers and farmers in designing, evaluating and implementing integrated weed management practices consistent with a given weed infestation. In recent years, many studies have been conducted to address reductions of herbicide inputs.

Information from this study (e.g. relations between density, years and crops) could be useful to a farmer in 
formulating a multiple-season weed management plan, especially since $C$. arvensis has been shown to have relatively stable patches over time and crop rotations in no-tillage systems.

\section{Acknowledgements}

This work was supported partially by a CICYT project (AGL 2002-04468-CO3-02).

\section{References}

Anonymous, 1998. Guía de agricultura de conservación de cultivos anuales. Asociación Española de Agricultura de Conservación, Suelos Vivos, p. 35.

Cambardella, C.A., Karlen, D.K., 1999. Spatial analysis of soil fertility parameters. Prec. Agric. 1, 5-11.

Cambardella, C.A., Moorman, T.B., Novak, J.M., Parkin, T.B., Karlen, D.K., Turco, R.F., Konopka, A.E., 1994. Field-scale variability of soil properties in central Iowa soils. Soil Sci. Soc. Am. J. 58, 1501-1511.

Cardina, J., Sparrow, D.H., McCoy, E.L., 1995. Analysis of spatial distribution of common lambsquarters (Chenopodium album) in no-till soybean (Glycine max). Weed Sci. 43, 258268.

Castro-Tendero, A.J., García-Torres, L., 1995. SEMAGI: an expert system for weed control decision making in sunflowers. Crop Prot. 14, 543-548.

Colbalch, N., Dessaint, F., Forcella, F., 1999. Evaluating field-scale sampling methods for the estimation of mean plant densities of weed. Weed Res. 40, 411-430.

Cousens, R., Croft, A.M., 2000. Weed populations and pathogens. Weed Res. 40, 63-82.

Dieleman, J.A., Mortensen, D.A., Wyse-Pester, D.Y., 1999. Influence of velvetleaf (Abutilon theophrasti) and common sunflower (Helianthus annuss) density variation on weed management outcomes. Weed Sci. 47, 81-89.

Dille, J.A., Milner, M., Groeteke, J.J., Mortensen, D.A., Williams, M.M., 2003. How good is your weed map? A comparison of spatial interpolators. Weed Sci. 51, 44-55.

Donald, W.W., 1994. Geostatistics for mapping weeds with a Canadian thistle (Cirsium arvense) patch as a case study. Weed Sci. 42, 648-657.

Gerhards, R., Wyse-Pester, D.Y., Mortensen, D., Johnson, G.A., 1997. Characterizing spatial stability of weed populations using interpolated maps. Weed Sci. 45, 108-119.

González-Andújar, J.L., Martínez-Cob, A., López-Granados, F., García-Torres, L., 2001. Spatial distribution and mapping of Orobanche crenata infestation in continuous Vicia faba cropping for six years. Weed Sci. 49, 773-779.

Heisel, T., Andersen, C., Ersbøll, A.K., 1996. Annual weed can be mapped with kriging. Weed Res. 36, 325-337.
Hevesi, J.A., Istok, J.D., FlintM, A.L., 1992. Precipitation estimation in mountains terrain using multivariate geostatistics. Part I. Structural analysis. J. Appl. Meteorol. 31, 661676.

Hidalgo, B., Saavedra, M., García-Torres, L., 1990. Weed flora of dryland crop in the Córdoba region (Spain). Weed Res. 30, 309-318.

Horowitz, M., 1973. Spatial growth of Sorghum halepense (L.). Pers. Weed Res. 13, 200-208.

Isaaks, E.H., Srivastava, R.M., 1989. An Introduction to Applied Geostatistics. Oxford University. New York.

Johnson, G.A., Mortensen, D.A., Gotway, C.A., 1996. Spatial and temporal analysis of weed seedling populations using geostatistics. Weed Sci. 44, 704-710.

Journel, A.G., 1986. Geostatistics: models and tools for the earth sciences. Math. Geol. 18, 119-140.

Jurado-Expósito, M., López-Granados, F., García-Torres, L., García-Ferrer, A., Sanchez de la Orden, M., Atenciano, S., 2003. Multi-species weed spatial variability and site-specific management maps in cultivated sunflower. Weed Sci. 51, 319328.

Liebman, M., Mohler, C.L., Staver, C.P., 2001. Ecological Management of Agricultural Weeds. Cambridge University Press, Cambridge.

López-Granados, F., Jurado-Expósito, M., Atenciano, S., García-Ferrer, A., Sanchez de la Orden, M., García-Torres, L., 2002. Spatial variability of agricultural soil parameters in southern Spain. Plant Soil 246, 97-105.

Lutman, P.J.W., Rew, L.J., Cussans, G.W., Miller, P.C.H., Paice, M.E.R., Stafford, D.J.E., 1998. Development of a patch spraying system to control weeds in winter wheat. Home-Grown Cereals Authority Project Report No. 158. HGCA, London.

Mortensen, D.A., Johnson, G.A., Young, L.J., 1993. Weed distribution in agricultural fields. In: Robert, P.C., Rust, R.H. (Eds.), Soil Specific Crop Management. Agronomy Society of America, Madison, WI, pp. 113-124.

Mortensen, D.A., Dielemann, J.A., Johnson, G.A., 1998. Weed spatial variation and weed management. In: Hatfield, J.L., Buhlerard, D.D., Stewart, B.A. (Eds.), Integrated Weed and Soil Management. Ann Arbor Press, Chelsea, MI, pp. 293309.

Rew, L.J., Cussans, G.W., 1995. Patch ecology and dynamics, how much we know? In: Proceedings 1995 Brighton Crop Protection Conference, Weeds, Brighton, UK, pp. 10591068.

Saavedra, M., García-Torres, L., Hernández-Bermejo, E., Hidalgo, B., 1989. Weed flora in the middle valley of Guadalquivir, Spain. Weed Res. 29, 167-179.

Webster, T.M., Cardina, J., 1998. Spatial and temporal emergence patterns of hemp dogbane (Apocynum cannabinum). In: Proceedings Weed Science Society of America, vol. 38, Chicago, IL, 1998, pp. 9-12.

Webster, T.M., Cardina, J., Woods, S.J., 2000. Spatial and temporal expansion patterns of Apocynum cannabinum patches. Weed Sci. $48,728-733$. 
Webster, R., Oliver, M.A., 2001. Geostatistics for Environmental Scientists. Wiley, Chichester, UK.

Wilson, B.J., Brain, P., 1991. Long-term stability of distribution of Alopecurus myosuroides Huds. within cereal fields. Weed Res. 31, 367-373.
Wyse, D.Y., 1996. Characterizing the stability of weed seedling populations. M.Sc. thesis, University of Nebraska, Lincoln, NE.

Zhang, N., Wang, M., 2002. Precision agriculture-a world overview. Comput. Electron. Agric. 36, 113-132. 